\title{
Tunable of Open-circuit Voltage in Bilayer Hybrid Solar Cells by Binary Polymer Blends
}

\author{
Xun-Heng YE, Yan-Yan ZHU and Fan WU*
}

Department of Applied Physics, Huzhou University, Huzhou, 313000, Zhejiang Province, China

*wufan@zjhu.edu.cn

Keywords: Hybrid Solar Cells, Polymer, $\mathrm{TiO}_{2}$, Interface.

\begin{abstract}
The different concentration of BPEI were blended into the MEḦPPV, and then respectively be composed into the MEH̃PPV/ZnO PHJ solar cells. Through calculating the dark reverse saturation current, we found that the interface barrier $\Phi_{\mathrm{B}}$ was changed. Interestingly, the open circuit voltage $\mathrm{V}_{\mathrm{oc}}$ was observed that changed linearly with the $\Phi_{\mathrm{B}}$. Through studying the relation of the $\mathrm{V}_{\mathrm{oc}}$ and $\Phi_{\mathrm{B}}$, we found that the open circuit voltage $\mathrm{V}_{\mathrm{oc}}$ can be tuned by the variation of $\Phi_{\mathrm{B}}$.
\end{abstract}

\section{Introduction}

Hybrid polymer-based solar cells (HPSCs) that use conjugated polymers as electron donor (D) and inorganic semiconductor nanocrystals as electron acceptor (A) had evoked a great wave of enthusiasm for the past few years. [1,2] The working principles, as well as the device performance and charge transfer modeling had also been studied gradually. [3, 4] Despite some achievements were obtained for understanding the mechanism of HPSCs in recent years, however, there was also not forming a complete and unified system in theoretical recognization on device physics, for example, there are some different viewpoints to recognize the factors that affect the open-circuit voltage $\left(V_{\mathrm{oc}}\right)$ : the $V_{\mathrm{oc}}$ can be enhanced by the superposition of the built-in field with the interfacial dipole of the interlayer; [5] the dissociation rate and decay rate of photo-induced electron-hole pairs also influence the open-circuit voltage; [6] the origin of this difference in the $V_{\text {oc }}$ has been proven to be directly related to the crystallization properties of active layer. [7]

In this paper, we fabricated the MEH-PPV/ZnO bilayer planar heterojunction solar cells, and added different concentration of branched-poly (ethylene mine) (BPEI) in MEH-PPV. Some new physical insights for the HPSCs were studied, which are not only simply reported the strategy of tuning $V_{\mathrm{oc}}$ for HPSCs, but also indicated some new physical quantity that closely related to $V_{\mathrm{oc}}$.

\section{Experimental}

\section{Device Fabrication}

ITO glass was cleaned sequentially, prior to use, by ultrasonic agitation twice in acetone, isopropanol and distilled water for $10 \mathrm{~min}$ in each washing process. For $\mathrm{ZnO} \mathrm{PHJ}$ device, The $\mathrm{ZnO}$ precursor was prepared from a mixture of zinc acetate aqueous solution $(1 \mathrm{~mL}, 0.1 \mathrm{M})$, ethanol (4 $\mathrm{mL}, \mathrm{AR})$, and acetic acid (0.1 mL, GR). The precursor was stirred for 1 hour after mixing. An etched ITO substrate was spin-coated with the precursor at $2000 \mathrm{rpm}$ for $50 \mathrm{~s}$ in ambient conditions (about $40 \mathrm{~nm}$ ). Then the $\mathrm{ZnO}$ film was annealed in air at $350{ }^{\circ} \mathrm{C}$ for $20 \mathrm{~min}$. The $\mathrm{TiO}_{2}$ sol-gel was prepared from a mixture of titanium tetraisopropoxide, absolute ethanol and acetic acid (GR, $\geq 99.8 \%$ ), in a volume ratio of 2:20:0.1. An etched ITO substrate was spin-coated with the $\mathrm{TiO}_{2}$ sol at $2000 \mathrm{rpm}$ for $50 \mathrm{~s}$ in ambient conditions. Then layer of MEH-PPV was spin coated (3000 rpm, 40 s) on oxide layer from a solution of MEH-PPV with BPEI of different concentration (weight ratio $\left.\mathrm{W}_{\text {BPEIIPPV }}=0 \%, 0.5 \%, 1 \%, 5 \%\right)$ in trichloromethane $(15 \mathrm{mg} / \mathrm{mL})$. After being dried in vacuum at room temperature for $24 \mathrm{~h}$, they are dried in vacuum at $100{ }^{\circ} \mathrm{C}$ for $30 \mathrm{~min}$ under vacuum. An Au top contact (100 nm thick) was deposited as $4 \mathrm{~mm}^{2}$ via thermal evaporation through a shadow mask. 


\section{Characterization}

The steady-state current-voltage $(\mathrm{J}-\mathrm{V})$ characteristic of the devices was measured on a controlled intensity modulated photo spectroscopy (CIMPS) (Zahner Co. Germany) in ambient conditions under an illumination through ITO glass side, using a blue light-emitting diode (LED) as light source (BLL01, $\lambda_{\max }=470 \mathrm{~nm}$, spectral half-width $=25 \mathrm{~nm}$, Zahner Co.) driven by a frequency response analyzer and the light intensity of $\mathrm{dc}$ component $\left(15.85 \mathrm{~mW} / \mathrm{cm}^{2}\right)$ was controlled by the bias voltage at the LED with a proportionality factor $\mathrm{FP}=315.7 \mathrm{~W} \cdot \mathrm{m}^{-2} \cdot \mathrm{V}^{-1}$, which was calibrated using an IL1400A photometer with a SEL 033/W detector (International Light, Inc., USA). Cyclic voltammetric $(\mathrm{CV})$ measurements were performed on an IM6e electrochemical workstation (Zahner Co., Germany) in $\mathrm{N}_{2}$ atmosphere at a scan rate of $50 \mathrm{mV} \mathrm{s}^{-1}$, with a platinum counter electrode.

\section{Results and Discussion}

Table 1. Performance of devices with different BPEI concentration measured under monochromatic illumination $\left(15.85 \mathrm{~mW} / \mathrm{cm}^{2}\right)$ at $470 \mathrm{~nm}$.

\begin{tabular}{|c|c|c|c|c|c|}
\hline $\begin{array}{l}\text { MEH-PPV/ZnO with } \\
\text { different } \\
\text { BPEI concentration }\end{array}$ & $\begin{array}{l}V_{\mathrm{oc}} \\
(\mathrm{V})\end{array}$ & )$_{\left(\mathrm{mA} / \mathrm{cm}^{2}\right.}^{J_{\mathrm{sc}}}$ & $\begin{array}{l}\mathrm{FF} \\
(\%)\end{array}$ & $\begin{array}{l}\eta \\
(\%)\end{array}$ & $\begin{array}{l}\Phi_{\mathrm{B}} \\
(\mathrm{eV})\end{array}$ \\
\hline $\mathrm{W}_{B P E I / P P V}=0.0 \%$ & 0.54 & 0.02 & 31.0 & 0.049 & $2.40 \times 10^{-7}$ \\
\hline $\mathrm{W}_{B P E I / P P V}=0.5 \%$ & 0.56 & 0.01 & 36.8 & 0.013 & $2.63 \times 10^{-7}$ \\
\hline $\mathrm{W}_{B P E I / P P V}=1.0 \%$ & 0.51 & 0.05 & 34.6 & 0.052 & $5.25 \times 10^{-7}$ \\
\hline $\mathrm{W}_{B P E I / P P V}=2.5 \%$ & 0.38 & 0.04 & 36.5 & 0.056 & $1.60 \times 10^{-6}$ \\
\hline $\mathrm{W}_{B P E I I P P V}=5.0 \%$ & 0.33 & 0.15 & 33.2 & 0.100 & $6.58 \times 10^{-6}$ \\
\hline $\begin{array}{l}\text { MEH-PPV/TiO } \\
\text { BPEI with no }\end{array}$ & 0.69 & 0.01 & 26.3 & 0.009 & $1.68 \times 10^{-9}$ \\
\hline
\end{tabular}

The performance of MEH-PPV/ZnO PHJ devices with different BPEI concentration were seen in the Table 1. The device performance is changed remarkably after addition BPEI into MEH-PPV matrix. After adding a BPEI concentration of $0.5 \mathrm{wt} \%$ in weight ratio, the short-circuit current increased slightly from $0.02 \mathrm{~mA} / \mathrm{cm}^{2}$ to $0.04 \mathrm{~mA} / \mathrm{cm}^{2}$, but when adding to $1.0 \mathrm{wt} \%$ in weight ratio, the short-circuit current enhanced to $0.15 \mathrm{~mA} / \mathrm{cm}^{2}$, which is the highest short-circuit current among the above $\mathrm{ZnO}$ devices. When the BPEI concentration surpass the $1.0 \mathrm{wt} \%$, the short-circuit current gradually decreased. The open-circuit voltage also changed after BPEI addition, basically, opencircuit voltage reduced as BPEI concentration increased from 0 to $1.0 \mathrm{wt} \%$, and the continue adding the BPEI, the open-circuit voltage will back-up. The changed device performance are similar to those found in the $\mathrm{P} 3 \mathrm{HT} / \mathrm{TiO}_{2}$ bulk heterojunction cells with different concentration of PMMA as an additive to blending into $\mathrm{P} 3 \mathrm{HT}$ and the $\mathrm{P} 3 \mathrm{HT} / \mathrm{TiO}_{2}$ bilayer cell with $\mathrm{BPEI}$ addition. $[8,9]$ 

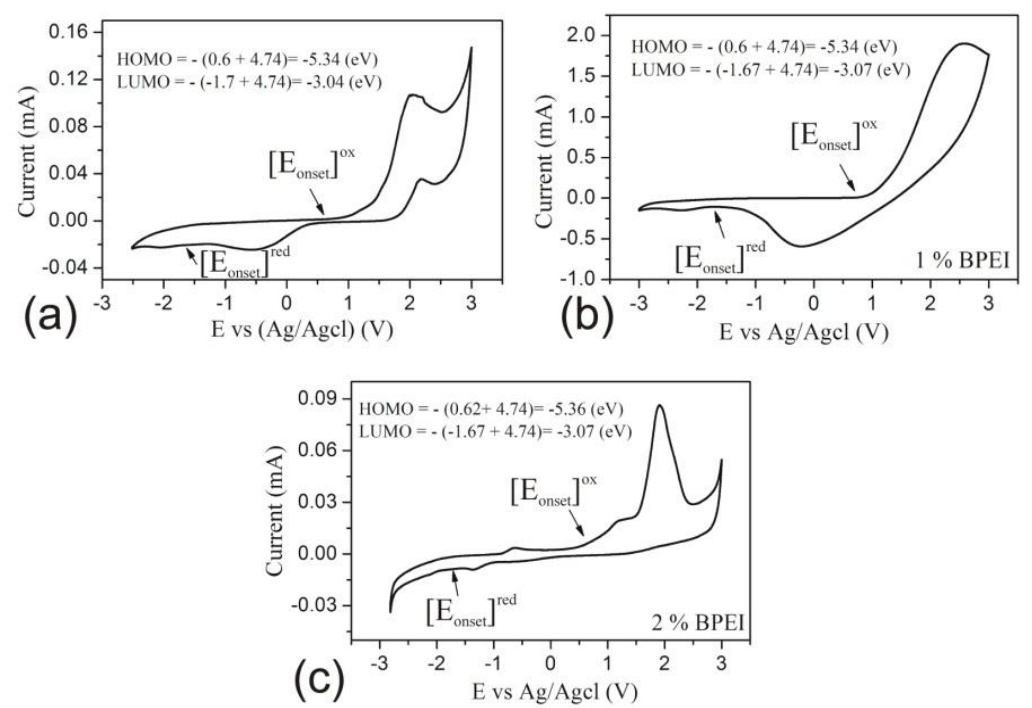

Fig. 1 The cyclic voltammetry characteristics for MEH-PPV/BPEI blends with different BPEI concentrations.

The various current had been explained as the different interfacial contact by adding proper the BPEI or the enhanced electrical conductivity by adding small amount of PMMA. [8, 9] However, the $V_{\text {oc }}$ had not been attentive researched, which causes us to search for the reason that why the voltage will changed after BPEI addition. First, the electrode materials unchanged in this experiment. Therefore, the effect of electrode work-functions on the $V_{\text {oc }}$ should be ruled out. Others had also experimentally demonstrated that the electrode work-function has no significant effect on

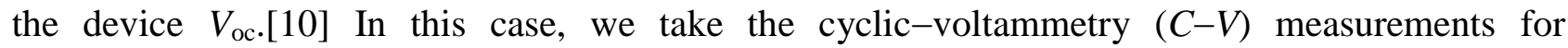
MEH-PPV/BPEI blends to sure that whether the change of the open-circuit voltage is by the change of the energy levels of MEH-PPV/BPEI blends. From the $C-V$ curve (in the Figure 1), we can see that the HOMO and LUMO of MEH-PPV were not largely changed by BPEI addition. Thus, it cannot help to ask that which factor play the key role on the open-circuit voltage.

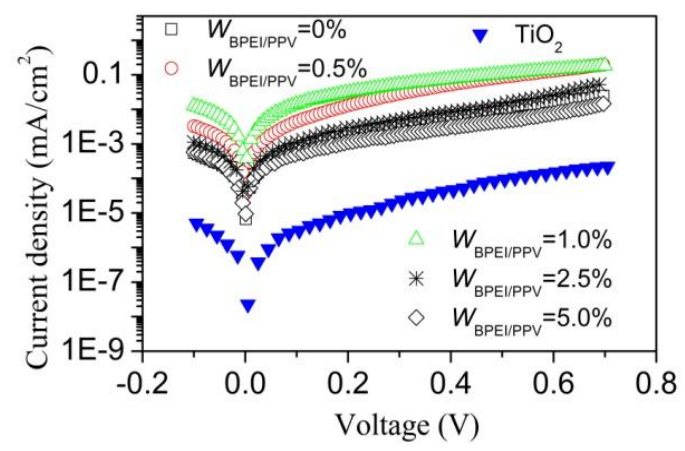

Fig. 2 Dark $J-V$ of the device for various $\mathrm{W}_{B P E I / P P V}$ of MEH-PPV/ZnO bilayer solar cells and MEH$\mathrm{PPV} / \mathrm{TiO}_{2}$ bilayer solar cells with no BPEI.

For answer this question, we deeply analysis the dark $J-V$ characteristic curves of our cells (Figure 2). The changed of reverse dark current which similar to the change of open-circuit voltage, which aroused our much interest. It has been demonstrated that there is often an interface activation energy barrier $\Phi_{\mathrm{B}}$ at the heterojunction. At present, the formation of the $\Phi_{\mathrm{B}}$ are usually explained as a result of the energy level bending by the vaccum level misalignments at the heterojunction or the formation of interface charge-transfer states,[11] and $\Phi_{\mathrm{B}}$ can be evaluated from the dark reverse saturation current in dark $J-V$ characteristic by: $[12,13]$ 


$$
J_{0}=B \exp \left(\frac{-q \phi_{\mathrm{B}}}{k T}\right)
$$

Where $B$ is a coefficient with a value in the range of $1000 \mathrm{~A} \mathrm{~cm}^{-2}, J_{0}$ is dark saturation current, $k$ is the Boltzmann constant, $T$ is the temperature constant, $q$ is the electron charge. Therefore, we extracted the approximate value of dark saturation current $J_{0}$ from the dark $J-V$ curve, which listed in Table 1 . Based on eq 1, we calculated the interface energy barrier $\Phi_{\mathrm{B}}$ values of all devices, the results also be listed in Table 1 .
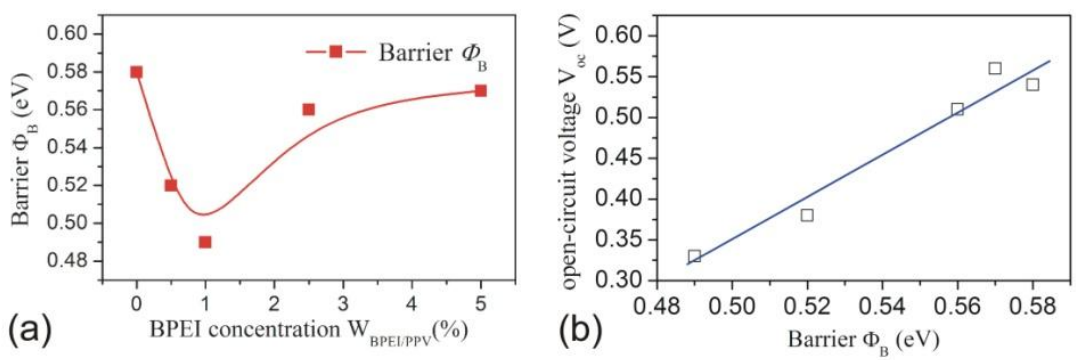

Fig. 3 (a) The plot of the relation of interface barrier $\Phi_{\mathrm{B}}$ with BPEI concentration. The inset Figure in (a) is the plot of the relation of open-circuit voltage with BPEI concentration. (b) The linear correlation of open-circuit voltage and the $\Phi_{\mathrm{B}}$.

As shown in Fig. 3a, the dependence of $\Phi_{\mathrm{B}}$ on BPEI concentration is the same as that of $V_{\mathrm{oc}}$. The $V_{\text {oc }} v s \Phi_{\mathrm{B}}$ plot in Fig. $3 \mathrm{~b}$ exhibits a good linear ship. These results indicate a direct correlation between $V_{\mathrm{oc}}$ and $\Phi_{\mathrm{B}}$. The mechanism of BPEI how to change the interface energy barrier $\Phi_{\mathrm{B}}$ had not clear; probably it caused the interface energy level bending by different degrees or the formation of interfacial hybrid charge-transfer states. [14] Although the mechanism is not very distinct, however, it not affects to conclude the relation of the $V_{\mathrm{oc}}$ and $\Phi_{\mathrm{B}}$. For further confirming the correlation of $V_{\mathrm{oc}}$ and $\Phi_{\mathrm{B}}$, we studied the $\mathrm{MEH}-\mathrm{PPV} / \mathrm{TiO}_{2} \mathrm{PHJ}$ cells without adding the BPEI. As the energy levels of $\mathrm{TiO}_{2}$ are the same to the $\mathrm{ZnO}$, if the $V_{\text {oc }}$ depended on the energies of the relevant energy levels at the D/A heterojunction, the $V_{\mathrm{oc}}$ in $\mathrm{TiO}_{2}$ cell should be close to the $\mathrm{ZnO}$ cell. However, the open-circuit voltage of $\mathrm{TiO}_{2}$ cell is much bigger than $\mathrm{ZnO}$ cells. The $V_{\text {oc }}$ of $\mathrm{TiO}_{2}$ cell is $0.69 \mathrm{~V}$, which is $0.15 \mathrm{~V}$ higher than the $\mathrm{ZnO}$ cell. According this deduce, the interface barrier in $\mathrm{TiO}_{2}$ cell should be higher than $\mathrm{ZnO}$ celling. $\mathrm{Be}$ as expected, the interface barrier in $\mathrm{TiO}_{2}$ cell is $0.71 \mathrm{eV}$ which is $0.13 \mathrm{eV}$ higher than the $\mathrm{ZnO}$ cell, even that the difference of $\Phi_{\mathrm{B}}$ values is close to the difference of $V_{\mathrm{oc}}$ values. That also explained that why the open-circuit voltage in $\mathrm{TiO}_{2}$ composed cells is higher than the $\mathrm{ZnO}$ composed cells.

Table 2 Listed device performances and $J-V$ characteristics parameters of P3HT/PCBM solar cells from literature. [15]

\begin{tabular}{llllll}
\hline Anneal & $V_{\mathrm{oc}}(\mathrm{V})$ & $J_{\mathrm{sc}}\left(\mathrm{mA} / \mathrm{cm}^{2}\right)$ & $\mathrm{FF}(\%)$ & $\eta(\%)$ & $\Phi_{\mathrm{B}}(\mathrm{eV})$ \\
\hline Before & 0.42 & 6.9 & 46 & 1.3 & $9.0 \times 10^{-7}$ \\
After & 0.59 & 7.7 & 58 & 2.7 & $3.6 \times 10^{-9}$
\end{tabular}

Otherwise, other group studies on the effects of thermal annealing before and after $\mathrm{Al}$ deposition on poly(3-hexylthiophene)(P3HT)/[6,6]-phenyl- $\mathrm{C}_{61}$ butyric acid methyl ester (PCBM) blend solar cells also certificate our conclusion. [15] The device performance datum which extracted from the paper is listed in Table 2. From the $J_{0}$ values in Table 2, the $\Phi_{\mathbf{B}}$ value can be calculated by eq (1), 
which are also shown in the Table 2. Obviously, the bigger of the barrier $\Phi_{\mathbf{B}}$, the higher of the $V_{\mathrm{oc}}$, and the growth amplitude of the $V_{\mathrm{oc}}$ is $0.17 \mathrm{~V}$, the $\Phi_{\mathbf{B}}$ is $0.14 \mathrm{eV}$, and the values are very close. This result effectively certificates our conclusion.

\section{Conclusions}

The different concentration of BPEI were blended into the MEH-PPV, and then respectively be composed into the $\mathrm{MEH}-\mathrm{PPV} / \mathrm{ZnO} \mathrm{PHJ}$ solar cells. Through calculating the dark reverse saturation current, we found that the interface barrier $\Phi_{\mathrm{B}}$ was changed. Simultaneously, the open-circuit voltage $V_{\mathrm{oc}}$ are also found that changed parallely with the interface barrier $\Phi_{\mathrm{B}}$. Through studying the relation of the $V_{\mathrm{oc}}$ and $\Phi_{\mathrm{B}}$, we found that the $V_{\mathrm{oc}}$ more correlated with the $\Phi_{\mathrm{B}}$.

\section{Acknowledgments}

We acknowledge the"1112 Talents Project" of Huzhou city, and the Foundation of Science and Technology Innovation Activities \& Emerging Talents Plan of Zhejiang Province (2015R427005; 2016R42707).

\section{References}

[1] L. Zheng, S. Han, H. Liu, P. Yu, X. Fang, Small12, 1527 (2016).

[2] G, Mariani.. R. B. Laghumavarapu, B. T. Villers, J. Shapiro, P. Senanayake, A. Lin, B. J. Schwartz, D. L. Huffaker, Appl. Phys. Lett.97, 013107 (2010).

[3] A. B. Guvenc, E. Yengel, G. Wang, C.S. Ozkan, M. Ozkan, Appl. Phys. Lett. 96, 143301 (2010).

[4] R. A. Street, M. Schoendorf, Phys. Rev. B81, 205307 (2010).

[5] J. Luo, H. Wu, C. He, A. Li, W. Yang, Y. Cao, Appl. Phys. Lett.95, 043301 (2009).

[6] Y. Shang, Q. Li, L. Meng, D. Wang, Z. Shuai, Appl. Phys. Lett. 97, 143511 (2010).

[7] A. Sánchez-Díaz, M. Izquierdo, S. Filippone, N. Martin, E. Palomares, Adv. Funct. Mater.20, 2695 (2010).

[8] M. Wu, H. Liao, H. Lo, S. Chen, Y. Lin, W. Y, T. Zeng, C. Chen, Y. Chen, W. Su, Sol. Energy Mater. Sol. Cells93, 961(2009).

[9] R. Peng, C. Chen, W. Shen, M. Wang, Y. Guo, H Geng, Acta. Phys. Sinica 58, 6582 (2009).

[10]E. Kymakis, I. Alexandrou, G. A. J. Amaratunga, J. Appl. Phys.93, 1764 (2003).

[11] J. William, J. R. Potscavage, S. Asha, K. Bernard, Accounts Chem. Res.42, 1758 (2009).

[12]B. Kippelen, J. Bredas, Energy Environ. Sci.2, 251 (2009).

[13]C. Dridi, V. Barlier, H, Chaabane, J. Davenas, H.B. Ouada, Nanotechnology 19, 375201(2008).

[14] A. Panda, K. Ding, X. Liu, S. R. Forrest, Phys. Rev. B94, 125429 (2016).

[15] A. Orimo, K. Masuda, S. Honda, H. Benten, S. Ito, H. Ohkita, H. Tsuji, Appl. Phys. Lett.96, 043305 (2010). 